\title{
Aplicabilidade da auriculoterapia em pacientes oncológicos: revisão integrativa da literatura
}

\author{
Applicability of auriculotherapy in cancer patients: an integrative literature review \\ Aplicabilidad de la auriculoterapia en pacientes con cáncer: una revisión integradora \\ de la literatura
}

Como citar este artigo:

Contim CLV, Espírito Santo FH, Moretto IG. Applicability of auriculotherapy in cancer patients: an integrative literature review. Rev Esc Enferm USP. 2020;54:e03609. doi: https://doi.org/10.1590/S1980-220X2019001503609

\section{Carolina Lélis Venâncio Contim ${ }^{1}$ \\ Fátima Helena do Espírito Santo ${ }^{2}$ \\ Isadora Górski Moretto ${ }^{1}$}

${ }^{1}$ Instituto Nacional de Câncer (INCA), Rio de Janeiro, RJ, Brasil.

${ }^{2}$ Universidade Federal Fluminense, Escola de Enfermagem Aurora de Afonso

Costa, Departamento de Enfermagem Médico-Cirúrgica, Niterói, RJ, Brasil.

\section{ABSTRACT}

Objective: To analyze scientific evidence in the literature on the use of auriculotherapy to relieve symptoms related to cancer and/or its treatment. Method: An integrative literature review based on: MEDLINE, CINAHL, LILACS, SCOPUS and COCHRANE in the last five years in English, Portuguese and Spanish. Inclusion criteria: primary studies with the central theme. Exclusion criteria: opinion articles, reviews and experience reports. Results: The search resulted in 435 publications, but only 11 remained after applying four selection stages. An analysis of the study designs showed that three of them $(27.5 \%)$ had a high level of evidence, three $(27.5 \%)$ had moderate, four $(36 \%)$ had low and one (9\%) had a very low level. The evaluated outcomes were related to the following symptoms: pain, constipation, nausea and vomiting, hot flashes, dyspnea, fatigue and insomnia. Moreover, $100 \%$ of the publications exposed positive effects of auriculotherapy in oncology. Conclusion: Auriculotherapy in cancer patients improves symptoms, and this practice was considered a safe and acceptable intervention. However, it is necessary to expand studies to obtain more favorable evidence since only 3 studies presented a high level of evidence.

\section{DESCRIPTORS}

Complementary Therapies; Auriculotherapy; Acupuncture, Ear; Neoplasms; Oncology Nursing; Review. 


\section{INTRODUÇÃO}

Atualmente, o câncer é um problema de saúde pública, classificado como uma doença crônico-degenerativa ${ }^{(1)} \mathrm{e}$ considerado um dos principais responsáveis pelo adoecimento e óbito da população mundial ${ }^{(2)}$. Estima-se para o Brasil, no biênio 2018-2019, a ocorrência de 600 mil casos novos de câncer, de forma que para cada ano, excetuando-se o câncer de pele não melanoma (cerca de 170 mil casos novos), poderão ocorrer 420 mil casos novos desta doença na população brasileira ${ }^{(2)}$.

Existem três formas principais de tratamentos convencionais utilizados para o câncer, que são: cirurgia, radioterapia e quimioterapia. Na maioria das vezes, esses tratamentos são indicados de forma concomitante e, atualmente, poucas são as neoplasias malignas que são abordadas com apenas um tipo de tratamento ${ }^{(3)}$. Essas modalidades de tratamento podem resultar em mudanças na aparência, nas habilidades e no desempenho das funções diárias dos pacientes. Nesse sentido, a quimioterapia merece destaque, pois devido a não especificidade das drogas no metabolismo celular, além de células malignas, o tratamento atinge também as células sadias do organismo e, consequentemente, pode gerar diversos efeitos adversos, como: anemia, fadiga, inapetência, alopecia, diarreia, perda de peso, mucosite, constipação, náuseas e vômitos, dor neuropática, entre outros. Associado com as reações físicas, os pacientes oncológicos vivenciam o sofrimento psíquico, no qual a dor física e a fragilidade frente a um tratamento agressivo tornam a situação de adoecimento de difícil convivência ${ }^{(4)}$.

O manejo de sintomas relacionados ao câncer e seu tratamento tem sido reconhecido como um grande desafio para os profissionais de saúde. Assim, o sofrimento causado por esses sintomas pode retardar o processo de reabilitação através do atraso dos tratamentos programados e até mesmo abandono dos mesmos. Além disso, quando os múltiplos sintomas são tratados individualmente com produtos farmacêuticos, a polifarmácia pode agravar ainda mais outros sintomas e levar a futuros problemas e interações medicamentosas ${ }^{(5)}$.

No mundo há uma crescente busca por medidas não farmacológicas e formas holísticas de cuidado e os motivos desse interesse incluem os efeitos colaterais comuns dos tratamentos medicamentosos e a insatisfação com o modelo de foco na doença e não na saúde dos indivíduos ${ }^{(6)}$. Por isso, têm se empregado práticas integrativas e complementares (PICS) associadas à terapêutica convencional, com o objetivo de favorecer o equilíbrio e o autocontrole dos pacientes $^{(7)}$.

As práticas integrativas e complementares (PICS) são compostas por abordagens de cuidado e de recursos terapêuticos, que buscam estimular os mecanismos naturais de prevenção de agravos e de recuperação da saúde por meio de tecnologias eficazes, seguras e menos invasivas com ênfase na escuta acolhedora, no desenvolvimento do vínculo terapêutico e na integração do ser humano com o meio ambiente e a sociedade. No Brasil, a legitimação e a institucionalização dessas abordagens de atenção à saúde teve início com a criação da Política Nacional de Práticas Integrativas e
Complementares (PNPIC), em 2006 ${ }^{(8)}$, essa política vem avançando e ampliando a oferta das PICS, e no ano de 2018 fazem parte de seu rol 29 práticas, são elas: Homeopatia, Medicina Tradicional Chinesa/Acupuntura, Ayurveda, Medicina Antroposófica, Naturopatia, Plantas Medicinais e Fitoterapia, Termalismo Social/Crenoterapia, Reiki, Yoga, Arteterapia, Biodança, Dança Circular, Meditação, Musicoterapia, Osteopatia, Quiropraxia, Reflexoterapia, Shantala, Terapia Comunitária Integrativa, Apiterapia, Aromaterapia, Bioenergética, Constelação Familiar, Cromoterapia, Geoterapia, Hipnoterapia, Imposição de mãos, Ozonioterapia, Terapia de Florais ${ }^{(9)}$.

A terapia auricular faz parte de um conjunto de técnicas terapêuticas baseada nos preceitos da Medicina Tradicional Chinesa (MTC), juntamente com a acupuntura corporal e é uma prática aprovada como especialidade e/ou qualificação para profissionais da Enfermagem, segundo a Resolução do Conselho Federal de Enfermagem (COFEN) 500/2015 ${ }^{(10)}$.

A auriculoterapia promove a regulação psíquico-orgânica do indivíduo por meio de estímulos nos pontos energéticos localizados na orelha, nos quais todo o organismo se encontra representado como um microssistema, e pode ser executada de forma complementar à terapêutica convencional. Para a aplicação da terapia auricular são utilizados materiais como: agulhas, cristais e sementes de mostarda, entre outros. Quando as sementes são utilizadas, esta prática pode ser denominada de acupressão auricular e se caracteriza por não utilizar materiais invasivos, ter fácil aplicabilidade e apresentar efeitos secundários mínimos ${ }^{(11)}$.

Considerando toda a problemática vivenciada pelos pacientes oncológicos associada a possibilidade do uso de práticas integrativas e complementares nessa área, o objetivo desta revisão foi analisar evidências científicas na literatura do uso da auriculoterapia no alívio de sintomas relacionados ao câncer e/ou seu tratamento.

\section{MÉTODO}

\section{TIPO DE ESTUdo}

Trata-se de uma revisão integrativa da literatura, que proporciona uma síntese dos dados científicos sobre determinado problema de pesquisa ${ }^{(12)} \mathrm{e}$ a aplicação dos resultados dos dados com evidências significativas na prática clínica ${ }^{(13)}$. Além disso, pode corroborar com as lacunas do conhecimento para investigações futuras. A revisão integrativa é elaborada a partir das seguintes etapas: desenvolvimento da questão norteadora; busca da literatura nas bases de dados; coleta de dados dos estudos; avaliação crítica dos estudos selecionados; análise e discussão dos resultados e apresentação da revisão integrativa ${ }^{(13)}$.

A questão norteadora desse estudo foi desenvolvida a partir do acrônimo PIO, em que $\mathrm{P}$ representa a população, que no presente estudo são os pacientes com câncer, o I é a intervenção que, no caso, é a auriculoterapia, e a letra $\mathrm{O}$ (outcomes) são os resultados, que são determinados pelos sintomas apresentados pelos pacientes ${ }^{(12)}$. Então, a questão norteadora estabelecida para esta revisão foi: a auriculoterapia é 
eficaz para aliviar sintomas de pacientes oncológicos, relacionados à evolução da doença e/ou seu tratamento?

\section{CRITÉrios de SELEÇÃo}

Na pré-seleção dos artigos foi empregado filtro temporal dos cinco últimos anos (2014, 2015, 2016, 2017 e 2018) e filtro de idiomas inglês, português e espanhol. A escolha dos descritores relacionados à intervenção auriculoterapia foi realizada após busca nas bases de dados de artigos que abordaram esta prática, para o reconhecimento de todos os termos possíveis empregados nos estudos e, para a combinação desses termos foram utilizados os operadores booleanos AND e OR.

A busca e a seleção dos artigos incluídos na revisão foram realizadas por dois revisores de forma independente e os resultados finais foram semelhantes. Essa dupla checagem faz parte da segunda etapa de elaboração de uma revisão integrativa, onde são estabelecidos os critérios para inclusão e exclusão de estudos/amostragem ou busca na literatura e garante a confiabilidade da pesquisa ${ }^{(13)}$.

Os estudos foram eleitos obedecendo aos seguintes critérios de inclusão: estudos primários que abordassem o tema central deste trabalho no formato de artigos científicos nacionais e internacionais. Foram excluídos: artigos de opinião, de revisões, de relato de experiência e de pesquisas ainda não concluídas.

A seleção dos estudos foi realizada por meio da leitura cuidadosa de títulos e de resumos, de modo que para a seleção final dos artigos foi realizada a leitura dos trabalhos na íntegra, sendo eleitos aqueles que apresentaram o uso da auriculoterapia no alívio de sintomas em pacientes oncológicos como tema central.

\section{Coleta de dados}

A busca bibliográfica foi realizada nos meses de setembro e outubro de 2018 nas bases de dados: Medical Literature Analysis (PubMed/MEDLINE), Cumulative Index to Nursing and Allied Health Literature (CINAHL), Literatura Latino-Americana e do Caribe em Ciências da Saúde (BVS/ LILACS), SCOPUS e COCHRANE. Na busca foram utilizados os Descritores em Ciências da Saúde (DeCs) e MeSH (Medical Subject Headings): Neoplasms/Neoplasias, Auriculotherapy/Auriculoterapia, Acupressure/Acupressão e Acupuncture, ear/Acupuntura auricular. Além desses, também foram utilizados o descritor da CINAHL Cancer pacients e a palavra-chave cancer/câncer, que foram combinados de formas diferentes para favorecer uma busca ampla dos estudos (Quadro 1).

Quadro 1 - Cruzamentos realizados de acordo com as bases de dados selecionadas - Niterói, RJ, Brasil, 2019.

\begin{tabular}{|c|c|}
\hline Bases de Dados & Cruzamentos \\
\hline PubMed/MEDLINE & Neoplasms OR Cancer AND Auriculotherapy OR Acupuncture, Ear OR Acupressure OR Acupuncture Points \\
\hline CINAHL & Neoplasms OR Cancer Patients AND Auriculotherapy OR Acupuncture, Ear OR Acupressure OR Acupuncture Points \\
\hline BVS/LILACS & $\begin{array}{l}\text { Neoplasms OR Neoplasias OR Cancer AND Auriculotherapy OR Auriculoterapia OR Acupuncture, Ear OR } \\
\text { Acupuntura auricular OR Acupressure OR Acupressão OR Acupuncture Points OR Pontos de acupuntura }\end{array}$ \\
\hline SCOPUS & Neoplasms OR Cancer AND Auriculotherapy OR Acupuncture, Ear OR Acupressure OR Acupuncture Points \\
\hline COCHRANE & Neoplasms OR Cancer AND Auriculotherapy OR Acupuncture, Ear OR Acupressure OR Acupuncture Points \\
\hline
\end{tabular}

A coleta dos dados dos estudos foi realizada utilizando o instrumento elaborado, proposto e validado por Ursi ${ }^{(14)}$, que apresenta os seguintes itens: identificação do artigo original, objetivos, características metodológicas do estudo, intervenções mensuradas, resultados encontrados e nível de evidência ${ }^{(15)}$.

\section{ANÁlISE E TRATAMENTO DOS DADOS}

O nível de evidência foi classificado de acordo com o sistema GRADE (Grading of Recommendations Assessment Development and Evaluation) e consiste em um instrumento abrangente e transparente para a avaliação da qualidade da evidência disponível, o que produz a confiança na informação utilizada e possibilita a definição de uma determinada recomendação, auxiliando o processo de tomada de decisão ${ }^{(16)}$.
De acordo com as diretrizes do sistema GRADE, a qualidade da evidência é classificada em quatro níveis: alta, moderada, baixa ou muito baixa. O ponto de partida da avaliação é a análise do delineamento da pesquisa. Desfechos resultantes de ensaios clínicos randomizados começam a avaliação com pontuação de alta qualidade (4 pontos), enquanto aqueles determinados por estudos observacionais iniciam como baixa qualidade (2 pontos). Posteriormente, é empregado um sistema de ponderação para diminuir ou aumentar a qualidade da evidência. Os fatores que podem diminuir a qualidade da evidência são: risco de viés (1), inconsistência dos resultados (2), evidência indireta (3), imprecisão (4) e viés de publicação (5). E os fatores que podem aumentar o nível da evidência estão relacionados com a grande magnitude do efeito (6), gradiente dose-resposta (7) e confundidores que reduziriam o efeito encontrado $(8)^{(16)}$. 


\section{Aspectos ÉtIcos}

O presente manuscrito dispensa o parecer do Comitê de Ética por não se tratar de pesquisa envolvendo seres humanos e sim de uma pesquisa bibliográfica na categoria de revisão de literatura.

\section{RESULTADOS}

A partir da busca nas bases de dados, o método de seleção e de inclusão dos estudos ocorreu seguindo as seguintes etapas: primeiro foram retirados os artigos duplicados e do total de 435 artigos foram excluídos 142. Em seguida, foi realizada a leitura dos títulos e resumos dos 293 artigos, de acordo com os critérios de inclusão. A partir daí, foram excluídos 277 artigos e se procedeu à leitura na íntegra de 16 artigos, sendo excluídos 5 artigos por não responderem à questão norteadora desta revisão e não atenderem ao objetivo do estudo. Portanto, a amostra final foi composta por 11 estudos selecionados. A Figura 1 esboça o processo de seleção dos estudos desta revisão integrativa.

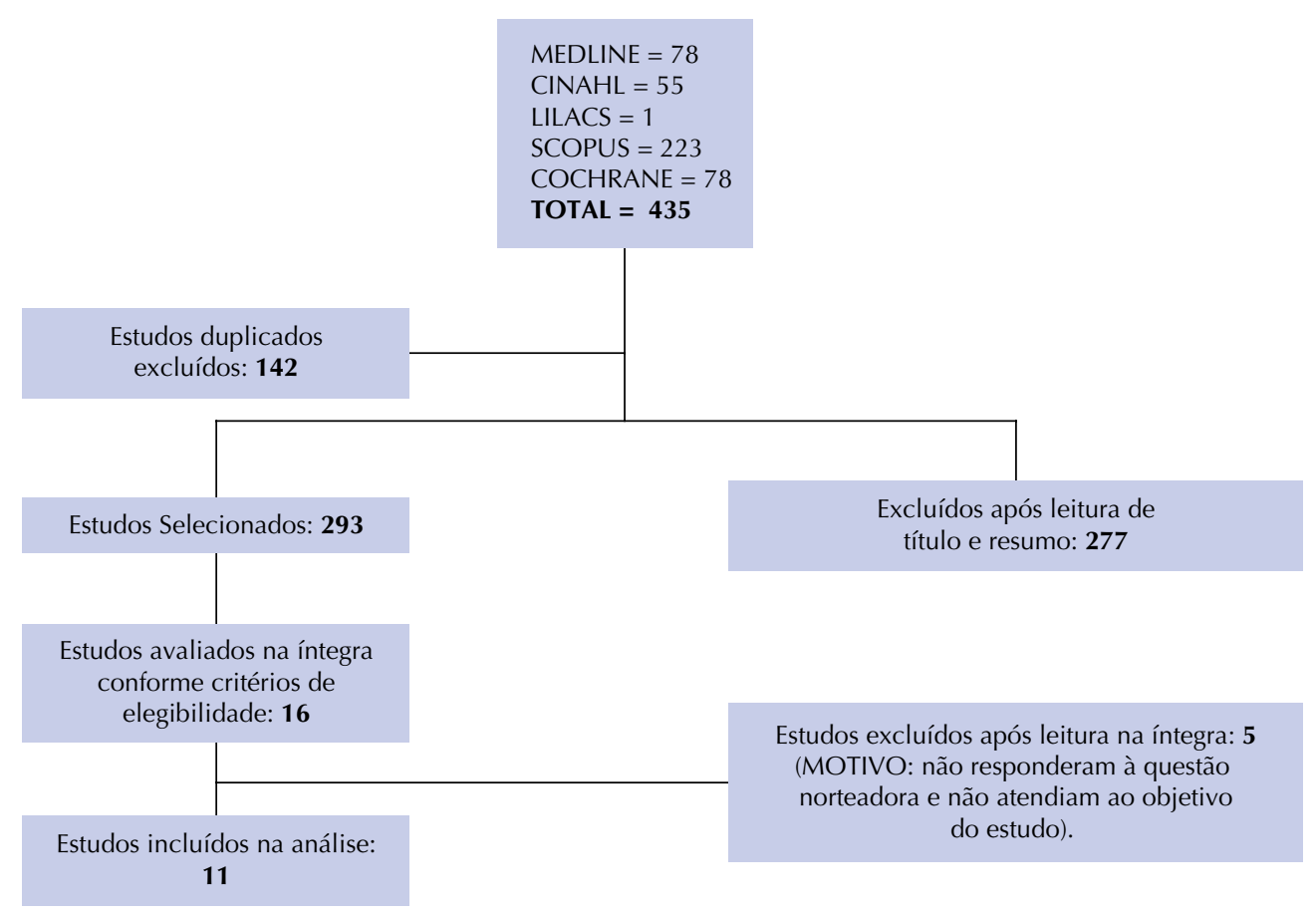

Figura 1 - Fluxograma de seleção e de inclusão dos estudos da revisão integrativa.

A partir da seleção dos estudos se obteve a amostra final de onze artigos, sendo o mais antigo publicado em 2015 e o mais recente em 2018, dos quais quatro $(36,5 \%)$ foram publicados em 2015, dois (18\%) em 2016, dois (18\%) em 2017 e três $(27,5 \%)$ em 2018. Em relação à origem dos estudos, todos foram publicados no idioma inglês e em periódicos internacionais, sendo seis $(54,5 \%)$ em periódicos de Enfermagem (entre esses, dois eram específicos de Enfermagem Oncológica), dois (18\%) em periódicos de Terapias Complementares, um (9\%) em periódico de Cuidados Paliativos, um (9\%) em periódico de Climatério e um (9\%) em periódico de Oncologia.

Entre os onze artigos selecionados, dez deles se repetiram e apareceram em mais de uma base de dados e foram recuperados oito $(72,7 \%)$ nas bases de dados PubMed/ MEDLINE, sete $(63,6 \%)$ na CINAHL, zero (0\%) na BVS/LILACS, onze (100\%) na SCOPUS e cinco $(45,5 \%)$ na COCHRANE. O único estudo encontrado na base de dados BVS/LILACS foi descartado por não se enquadrar nos critérios de inclusão, o que representa a não inserção de estudos nacionais e nem latino-americanos nesta revisão.

Em relação à localização da realização dos estudos, quatro (36,5\%) foram realizados no continente Americano, exclusivamente nos Estados Unidos da América (EUA), dois (18\%) no continente Europeu, na França e Inglaterra e, cinco $(45,5 \%)$ no continente Asiático com destaque para a Coreia do Sul com dois trabalhos, um na China, um em Taiwan e um no Irã. Identificou-se que houve a participação de Enfermeiros em dez (91\%) estudos, enquanto um artigo (9\%) refere somente a participação de Médicos.

Em se tratando do método, houve a predominância de delineamento Quantitativo para todos os onze artigos analisados (100\%), entre os quais dez estudos (91\%) apresentaram estudos experimentais, sendo sete $(63,5 \%)$ Ensaios Clínicos Randomizados e três (27,5\%) Quase Experimentos. E apenas um estudo (9\%) era de natureza observacional retrospectivo. A análise dos desenhos dos estudos selecionados mostrou que três estudos $(27,5 \%)$ apresentaram nível de evidência alto, três $(27,5 \%)$ 
moderado, quatro (36\%) baixo e somente um (9\%) muito baixo. Esses dados estão inseridos no Quadro 2 com o detalhamento das pontuações das publicações incluídas na revisão, de acordo com o sistema GRADE.
Apesar da seleção somente de estudos quantitativos, seis estudos experimentais (54,5\%) são estudos piloto e sugerem que as descobertas confirmam a viabilidade de estudos com uma amostra maior e representativa.

Quadro 2 - Nível de evidência dos estudos, segundo sistema GRADE ${ }^{(16)}$ - Niterói, RJ, Brasil, 2019.

\begin{tabular}{|c|c|c|c|c|c|c|c|c|c|c|}
\hline \multirow[t]{2}{*}{ Autor/Ano } & \multirow[t]{2}{*}{ Desenho do estudo } & \multicolumn{5}{|c|}{ Fatores de diminuição } & \multicolumn{3}{|c|}{$\begin{array}{l}\text { Fatores de } \\
\text { aumento }\end{array}$} & \multirow[t]{2}{*}{ Nível de evidência } \\
\hline & & 1 & 2 & 3 & 4 & 5 & 6 & 7 & 8 & \\
\hline C1: Yeh CH, et al; $2017^{(15)}$. & $\begin{array}{l}\text { Estudo Quase } \\
\text { Experimental }\end{array}$ & -1 & / & / & -1 & / & / & / & / & Baixo - 2 pontos \\
\hline C2: Shin J, et al; $2018^{(16)}$. & $\begin{array}{l}\text { Ensaio Clínico } \\
\text { Randomizado }\end{array}$ & -1 & / & / & / & / & / & / & / & Moderado - 3 pontos \\
\hline C3: Eghbali M, et al; $2016^{(17)}$. & $\begin{array}{l}\text { Ensaio Clínico } \\
\text { Randomizado }\end{array}$ & / & / & / & l & l & / & / & / & Alto - 4 pontos \\
\hline C4: Viel E, et al; $2016^{(18)}$. & $\begin{array}{l}\text { Estudo Observacional } \\
\text { Retrospectivo }\end{array}$ & / & -1 & l & l & / & / & / & / & Muito Baixo - 1 ponto \\
\hline C5: Strong RA, et al; $2015^{(19)}$. & $\begin{array}{l}\text { Ensaio Clínico } \\
\text { Randomizado }\end{array}$ & / & / & / & -1 & -1 & / & / & / & Baixo - 2 pontos \\
\hline C6: Yeh $\mathrm{CH}$, et al; $2015^{(5)}$. & $\begin{array}{l}\text { Ensaio Clínico } \\
\text { Randomizado }\end{array}$ & / & / & / & l & / & / & / & / & Alto - 4 pontos \\
\hline C7: Yeh CH, et al; $2015^{(20)}$. & $\begin{array}{l}\text { Estudo Quase } \\
\text { Experimental }\end{array}$ & -1 & -1 & / & / & / & $1+$ & / & / & Moderado - 3 pontos \\
\hline C8: Shin N, et al; $2018^{(21)}$. & $\begin{array}{l}\text { Estudo Quase } \\
\text { Experimental }\end{array}$ & -1 & -1 & / & l & / & / & / & / & Baixo - 2 pontos \\
\hline C9: Kuo HC, et al; $2018^{(22)}$. & $\begin{array}{l}\text { Ensaio Clínico } \\
\text { Randomizado }\end{array}$ & -1 & l & l & / & / & / & / & / & Moderado - 3 pontos \\
\hline C10: Li Y, et al; $2017^{(23)}$. & $\begin{array}{l}\text { Ensaio Clínico } \\
\text { Randomizado }\end{array}$ & / & / & / & l & / & / & / & / & Alto - 4 pontos \\
\hline $\begin{array}{l}\text { C11: Hughes JG, et al; } \\
2015^{(24)} \text {. }\end{array}$ & $\begin{array}{l}\text { Ensaio Clínico } \\
\text { Randomizado }\end{array}$ & I & I & l & -1 & -1 & / & / & / & Baixo - 2 pontos \\
\hline
\end{tabular}

1- Risco de viés; 2- Inconsistência; 3- Evidência Indireta; 4- Imprecisão; 5- Viés de Publicação; 6- Tamanho do efeito; 7- Gradiente de dose-resposta; 8- Possível confusão residual.

* As barras significam que no determinado aspecto o estudo não obteve dedução ou acréscimo de pontuação.

A caracterização dos estudos incluídos na revisão está sintetizada no Quadro 3 e organizada de acordo com os autores, título do artigo, ano de publicação, objetivos com o sintoma abordado em destaque, amostra, intervenção, mensuração, principais resultados, recomendações, conclusões e linha de tratamento utilizada. Os estudos foram agrupados de acordo com os sintomas apresentados pelos pacientes, no qual foram avaliados desfechos relacionados à aplicabilidade da auriculoterapia.

Quadro 3 - Síntese das características dos estudos incluídos na revisão de acordo com os autores, título do artigo, ano de publicação, sintoma abordado, intervenção, mensuração, principais resultados e conclusões e linha de tratamento utilizada - Niterói, RJ, Brasil, 2019.

\begin{tabular}{|c|c|c|c|c|c|c|c|}
\hline Artigo & $\begin{array}{l}\text { Tipo de } \\
\text { Estudo }\end{array}$ & Objetivo & Amostra & Intervenção & Mensuração & Resultados/Conclusões & $\begin{array}{c}\text { Linha de } \\
\text { tratamento }\end{array}$ \\
\hline \multicolumn{8}{|c|}{ Grupo 1: Dor } \\
\hline $\begin{array}{l}\text { C1: Yeh } \mathrm{CH}, \\
\text { et al; } 2017^{(17)} \text {. } \\
\text { Auricular point } \\
\text { acupressure } \\
\text { to manage } \\
\text { aromatase } \\
\text { inhibitor- } \\
\text { induced } \\
\text { arthralgia in } \\
\text { postmenopausal } \\
\text { breast cancer } \\
\text { survivors: a pilot } \\
\text { study. }\end{array}$ & $\mathrm{EQE}^{\mathrm{a}}$ & $\begin{array}{c}\text { Avaliar a } \\
\text { viabilidade } \\
\text { da acupressão } \\
\text { auricular } \\
\text { pontual no } \\
\text { manejo da } \\
\text { artralgia } \\
\text { induzida pelo } \\
\text { inibidor da } \\
\text { aromatase. }\end{array}$ & $\begin{array}{c}20 \text { mulheres } \\
\text { sobreviventes } \\
\text { do Câncer } \\
\text { de mama } \\
\text { com artralgia } \\
\text { induzida por } \\
\text { inibidor de } \\
\text { aromatase. }\end{array}$ & $\begin{array}{l}\text { Terapia auricular } \\
\text { bilateral com } \\
\text { sementes } 1 \text { vez por } \\
\text { semana durante } 4 \\
\text { semanas. Pontos } \\
\text { auriculares: } \\
\text { correspondentes à } \\
\text { localização da dor } \\
\text { e três pontos para } \\
\text { aliviar o stress e a dor } \\
\text { (shenmen, subcórtex } \\
\text { e simpático). }\end{array}$ & $\begin{array}{l}\text { Formulário Brief } \\
\text { Pain Inventory } \\
\text { - Short (BPISF) } \\
\text { para avaliação da } \\
\text { gravidade da dor, } \\
\text { o impacto da dor } \\
\text { na função diária, } \\
\text { a localização } \\
\text { da dor e uso } \\
\text { de analgésicos. } \\
\text { E amostras de } \\
\text { sangue (Citocinas } \\
\text { e quimiocinas } \\
\text { inflamatórias). }\end{array}$ & $\begin{array}{l}\text { A pontuação média de pior } \\
\text { dor observada diminuiu } 27 \% \\
\text { ( } p=0,05) \text { após o primeiro dia } \\
\text { da intervenção e alcançou } \\
\text { a maior redução } 63 \% \\
\text { ( } p<0,0001 \text { ) no dia } 28 \text {. As } \\
\text { citocinas e quimiocinas pró- } \\
\text { inflamatórias apresentaram } \\
\text { uma tendência de redução } \\
\text { percentual média. A } \\
\text { acupressão auricular é viável e } \\
\text { pode ser eficaz no controle da } \\
\text { artralgia em sobreviventes de } \\
\text { câncer de mama. }\end{array}$ & Chinesa \\
\hline
\end{tabular}




\begin{tabular}{|c|c|c|c|c|c|c|c|}
\hline Artigo & $\begin{array}{l}\text { Tipo de } \\
\text { Estudo }\end{array}$ & Objetivo & Amostra & Intervenção & Mensuração & Resultados/ Conclusões & $\begin{array}{l}\text { Linha de } \\
\text { tratamento }\end{array}$ \\
\hline $\begin{array}{l}\text { C6: } \\
\text { Yeh } \mathrm{CH} \text {, et al; } \\
2015^{(5)} \text {. Pilot } \\
\text { randomized } \\
\text { controlled trial } \\
\text { of auricular } \\
\text { point } \\
\text { acupressure to } \\
\text { manage } \\
\text { symptom } \\
\text { clusters of } \\
\text { pain, fatigue, } \\
\text { and disturbed } \\
\text { sleep in breast } \\
\text { cancer } \\
\text { patients. }\end{array}$ & $\mathrm{ECR}^{\mathrm{b}}$ & $\begin{array}{c}\text { Avaliar a } \\
\text { viabilidade e } \\
\text { tolerabilidade } \\
\text { da intervenção } \\
\text { da acupressão } \\
\text { auricular para } \\
\text { controlar a } \\
\text { dor, fadiga } \\
\text { e distúrbios } \\
\text { do sono em } \\
\text { pacientes com } \\
\text { câncer de } \\
\text { mama. }\end{array}$ & $\begin{array}{l}31 \text { mulheres } \\
\text { com câncer de } \\
\text { mama foram } \\
\text { randomizadas } \\
\text { para um grupo } \\
\text { intervenção ( } \mathrm{n} \\
=16) \text { ou um } \\
\text { grupo controle } \\
\text { - placebo ( } \mathrm{n}= \\
15) .\end{array}$ & $\begin{array}{c}\text { Auriculoterapia } \\
\text { com semente } 1 \\
\text { vez por semana } \\
\text { durante } 4 \text { semanas. } \\
\text { Pontos auriculares: } \\
\text { shenmen, simpático, } \\
\text { occipital, sucórtex e } \\
\text { ansiedade associados } \\
\text { aos pontos } \\
\text { relacionados a dor } \\
\text { em diferentes locais } \\
\text { (8 a } 12 \text { pontos). }\end{array}$ & $\begin{array}{c}\text { Escala M. D. } \\
\text { Anderson Symptom } \\
\text { Inventory (MDASI) } \\
\text { de avaliação da } \\
\text { gravidade dos } \\
\text { sintomas e de } \\
\text { interferência nas } \\
\text { atividades diárias, } \\
\text { além de um } \\
\text { questionário de } \\
\text { qualidade de vida } \\
\text { (WHOQOL-BREF). }\end{array}$ & $\begin{array}{l}\text { Os participantes do tratamento } \\
\text { ativo com auriculoterapia } \\
\text { relataram uma redução de } \\
71 \% \text { na dor ( } p=0,0217), \\
44 \% \text { na fadiga }(p=0,2351), \\
31 \% \text { no distúrbio do sono } \\
\text { ( } p=0,0642) \text { e } 61 \%(p=0,2792) \\
\text { na interferência nas } \\
\text { atividades diárias. Então, a } \\
\text { auriculoterapia pode fornecer } \\
\text { uma abordagem complementar } \\
\text { barata e eficaz para o } \\
\text { gerenciamento de grupos de } \\
\text { sintomas para pacientes com } \\
\text { câncer de mama. }\end{array}$ & Chinesa \\
\hline $\begin{array}{l}\text { C7: Yeh } \mathrm{CH}, \\
\text { et al; } 2015^{(22)} \text {. } \\
\text { Auricular point } \\
\text { acupressure } \\
\text { as an adjunct } \\
\text { analgesic } \\
\text { treatment } \\
\text { for cancer } \\
\text { patients: a } \\
\text { feasibility } \\
\text { study. }\end{array}$ & $\mathrm{EQE}^{\mathrm{a}}$ & $\begin{array}{c}\text { Examinar a } \\
\text { viabilidade } \\
\text { de um } \\
\text { protocolo de } \\
\text { auriculoterapia } \\
\text { em termos de } \\
\text { recrutamento } \\
\text { para a avaliação } \\
\text { e gestão da dor } \\
\text { em pacientes } \\
\text { com câncer. }\end{array}$ & $\begin{array}{c}50 \text { participantes } \\
\text { com diagnóstico } \\
\text { de câncer com } \\
\text { intensidade }> \\
\text { ou }=\text { a } 3 \text { pontos } \\
\text { em uma escala } \\
\text { numérica de dor } \\
\text { de } 11 \text { pontos } \\
\text { no momento do } \\
\text { recrutamento. }\end{array}$ & $\begin{array}{l}\text { Auriculoterapia com } \\
\text { sementes por } 7 \text { dias. } \\
\text { Pontos auriculares: } \\
\text { dois pontos fixos } \\
\text { (subcórtex e } \\
\text { simpático) e os } \\
\text { correspondentes } \\
\text { pontos de dor (total } \\
\text { de } 5 \text { a } 9 \text { pontos). } \\
\text { Coleta realizada } \\
\text { diariamente por } \\
7 \text { dias sobre a } \\
\text { intensidade da dor e } \\
\text { uso de medicação. }\end{array}$ & $\begin{array}{c}\text { Formulário Brief } \\
\text { Pain Inventory (BPI) } \\
\text { foi utilizado para } \\
\text { avaliar a gravidade } \\
\text { e impacto da } \\
\text { dor nas funções } \\
\text { diárias nas últimas } \\
24 \text { horas. Esta } \\
\text { avaliação incluiu } \\
\text { intensidade e } \\
\text { interferência da } \\
\text { dor, medicação } \\
\text { utilizada e alívio da } \\
\text { dor por medicação. }\end{array}$ & $\begin{array}{c}\text { A auriculoterapia reduziu a } \\
\text { intensidade da dor em mais de } \\
55 \% \text { para "pior dor" } \\
\text { ( } \mathrm{p}<0,0001 \text { ) e cerca de } 57 \% \\
\text { para "dor média" ( } \mathrm{p}<0,0001) \\
\text { e "intensidade da dor" } \\
\text { (p<0,0001). Um dos principais } \\
\text { resultados deste estudo é } \\
\text { a diminuição do uso de } \\
\text { medicação (78\%) para dor, } \\
\text { o que pode ter um efeito } \\
\text { positivo na diminuição do } \\
\text { risco de problemas potenciais } \\
\text { relacionados ao uso de } \\
\text { analgésicos, em pacientes com } \\
\text { câncer. A terapia auricular } \\
\text { pode ser implementada na } \\
\text { prática clínica como uma } \\
\text { intervenção não invasiva e } \\
\text { eficaz para o manejo da dor } \\
\text { relacionada ao câncer. }\end{array}$ & Chinesa \\
\hline \multicolumn{8}{|c|}{ Grupo 2: Constipação } \\
\hline $\begin{array}{l}\text { C2: Shin J, et } \\
\text { al; } 2018^{(18)} \text {. } \\
\text { Effects of } \\
\text { auricular } \\
\text { acupressure on } \\
\text { constipation in } \\
\text { patients with } \\
\text { breast cancer } \\
\text { receiving } \\
\text { chemotherapy: } \\
\text { a randomized } \\
\text { control trial. }\end{array}$ & $\mathrm{ECR}^{\mathrm{b}}$ & $\begin{array}{l}\text { Examinar os } \\
\text { efeitos da } \\
\text { acupressão } \\
\text { auricular } \\
\text { para aliviar a } \\
\text { constipação } \\
\text { em pacientes } \\
\text { com câncer } \\
\text { de mama } \\
\text { submetidos à } \\
\text { quimioterapia. }\end{array}$ & $\begin{array}{l}52 \text { participantes } \\
\text { com câncer } \\
\text { de mama } \\
\text { recebendo } \\
\text { quimioterapia } \\
\text { foram } \\
\text { randomizados } \\
\text { para um grupo } \\
\text { intervenção ( } \mathrm{n}= \\
\text { 26) ou um grupo } \\
\text { controle ( } \mathrm{n}= \\
26) .\end{array}$ & $\begin{array}{l}\text { Acupressão auricular } \\
\text { com sementes } 1 \\
\text { vez por semana, } \\
\text { por } 6 \text { semanas } \\
\text { consecutivas. Pontos } \\
\text { auriculares: intestino, } \\
\text { reto, San Jiao, baço, } \\
\text { pulmão, simpático e } \\
\text { subcórtex. O grupo } \\
\text { controle recebeu os } \\
\text { cuidados habituais. }\end{array}$ & $\begin{array}{c}\text { Escalas de } \\
\text { avaliação da } \\
\text { constipação } \\
\text { - Constipation } \\
\text { Assessment Scale } \\
\text { (CAS), forma das } \\
\text { fezes - Bristol } \\
\text { Stool Form (BSF) } \\
\text { e do efeito da } \\
\text { constipação na } \\
\text { vida diária - Patient } \\
\text { Assessment of } \\
\text { Constipation- } \\
\text { Quality of Life } \\
\text { (PAC-QOL). }\end{array}$ & $\begin{array}{c}\text { Os participantes do grupo } \\
\text { intervenção tiveram escores } \\
\text { reduzidos na avaliação da } \\
\text { constipação ( } p<0,001 \text { ), escores } \\
\text { aumentados na forma das fezes } \\
\text { ( } p=0,003 \text { ) e escores reduzidos } \\
\text { no efeito da constipação na } \\
\text { vida diária ( } p<0,001 \text { ) em } \\
\text { comparação ao grupo controle. } \\
\text { A acupressão auricular foi } \\
\text { considerada uma intervenção } \\
\text { de enfermagem segura, } \\
\text { aceitável e eficaz no alívio } \\
\text { da constipação em pacientes } \\
\text { com câncer de mama em } \\
\text { quimioterapia. }\end{array}$ & Chinesa \\
\hline $\begin{array}{l}\text { C10: Li Y, et } \\
\text { al; 2017 } \\
\text { Effect of } \\
\text { auricular points } \\
\text { treatment } \\
\text { combined } \\
\text { with acupoints } \\
\text { application in } \\
\text { patients with } \\
\text { constipation } \\
\text { after lung } \\
\text { cancer surgery. }\end{array}$ & $\mathrm{ECR}^{\mathrm{b}}$ & $\begin{array}{c}\text { Avaliar o efeito } \\
\text { do tratamento } \\
\text { de pontos } \\
\text { auriculares } \\
\text { combinado com } \\
\text { a aplicação } \\
\text { de pontos de } \\
\text { acupuntura em } \\
\text { paciente com } \\
\text { constipação } \\
\text { após cirurgia } \\
\text { de câncer de } \\
\text { pulmão. }\end{array}$ & $\begin{array}{c}341 \text { pacientes } \\
\text { com câncer de } \\
\text { pulmão entre } \\
50 \text { e } 70 \text { anos, } \\
\text { após lobectomia } \\
\text { pulmonar foram } \\
\text { randomizados } \\
\text { no grupo } \\
\text { experimental } \\
\text { (n=174) e no } \\
\text { grupo controle } \\
(\mathrm{n}=167) .\end{array}$ & $\begin{array}{l}\text { Auriculoterapia com } \\
\text { sementes* durante } 1 \\
\text { semana combinado } \\
\text { com acupuntura, } \\
\text { além da assistência } \\
\text { de enfermagem } \\
\text { de rotina (apoio } \\
\text { psicológico, } \\
\text { orientação sobre } \\
\text { dieta e sobre } \\
\text { as atividades } \\
\text { pós-operatórias). } \\
\text { O grupo controle } \\
\text { recebeu somente } \\
\text { cuidados de } \\
\text { enfermagem de } \\
\text { rotina. }\end{array}$ & $\begin{array}{c}\text { Escala Bristol } \\
\text { Stool Scale para } \\
\text { avaliação da } \\
\text { forma das fezes. } \\
\text { Foi considerado } \\
\text { constipação pós- } \\
\text { operatória após } 3 \\
\text { dias de ausência } \\
\text { de evacuação pós- } \\
\text { operação. }\end{array}$ & $\begin{array}{c}\text { Comparados aos dois grupos } \\
\text { de constipação, a incidência } \\
\text { de constipação no grupo } \\
\text { controle foi maior do que no } \\
\text { grupo experimental ( } p<0,001 \text { ) } \\
\text { e as características das fezes } \\
\text { do grupo experimental foram } \\
\text { melhores do que no grupo } \\
\text { controle (p=0,047). As medidas } \\
\text { de rotina para prevenir a } \\
\text { constipação após a cirurgia de } \\
\text { câncer de pulmão, mais pontos } \\
\text { de fixação auricular combinado } \\
\text { com pontos de acupuntura } \\
\text { podem efetivamente diminuir } \\
\text { a incidência de constipação } \\
\text { pós-operatória. }\end{array}$ & Chinesa \\
\hline
\end{tabular}


...continuação

\begin{tabular}{|c|c|c|c|c|c|c|c|}
\hline Artigo & $\begin{array}{l}\text { Tipo de } \\
\text { Estudo }\end{array}$ & Objetivo & Amostra & Intervenção & Mensuração & Resultados/ Conclusões & $\begin{array}{l}\text { Linha de } \\
\text { tratamento }\end{array}$ \\
\hline \multicolumn{8}{|c|}{ Grupo 3: Náuseas e vômitos } \\
\hline $\begin{array}{l}\text { C3: Eghbali M, } \\
\text { et al; } 2016^{(19)} \text {. } \\
\text { The effect } \\
\text { of auricular } \\
\text { acupressure } \\
\text { on nausea } \\
\text { and vomiting } \\
\text { caused by } \\
\text { chemotherapy } \\
\text { among } \\
\text { breast cancer } \\
\text { patients. }\end{array}$ & $\mathrm{ECR}^{\mathrm{b}}$ & $\begin{array}{c}\text { Determinar } \\
\text { o efeito da } \\
\text { acupressão } \\
\text { auricular } \\
\text { no alívio de } \\
\text { náuseas e } \\
\text { vômitos entre } \\
\text { as mulheres } \\
\text { que receberam } \\
\text { quimioterapia. }\end{array}$ & $\begin{array}{c}48 \text { mulheres } \\
\text { em tratamento } \\
\text { quimioterápico } \\
\text { com drogas } \\
\text { como cisplatina } \\
\text { e antraciclina } \\
\text { foram } \\
\text { randomizadas } \\
\text { para grupo } \\
\text { experimental e } \\
\text { grupo controle. }\end{array}$ & \begin{tabular}{|} 
Terapia auricular \\
em 1 ciclo de \\
quimioterapia com \\
sementes mantidas \\
por 5 dias. Pontos \\
auriculares: zero, \\
estômago, tronco \\
cerebral, shenmen e \\
coração e medicação \\
antiemética padrão. \\
O grupo controle \\
recebeu apenas a \\
medicação padrão. \\
Quando os pacientes \\
foram encaminhados \\
para a quimioterapia \\
seguinte a posição \\
dos dois grupos se \\
inverteram.
\end{tabular} & \begin{tabular}{|} 
Questionário \\
Morrow standard \\
questionnaire para \\
avaliar as náuseas \\
e vômitos antes, \\
durante e após \\
a quimioterapia, \\
sua duração, \\
intensidade e \\
tempo de duração \\
com uma escala de \\
Likert de 7 graus.
\end{tabular} & $\begin{array}{l}\text { O uso de terapia auricular } \\
\text { levou à diminuição do número } \\
\text { e intensidade de náuseas e } \\
\text { vômitos nas fases aguda e } \\
\text { tardia no grupo experimental, } \\
\text { que foram significativamente } \\
\text { menores do que no grupo } \\
\text { controle }(p=0,001) \text {. O uso de } \\
\text { terapia auricular em pontos } \\
\text { recomendados, juntamente } \\
\text { com outras terapias médicas, } \\
\text { pode aliviar náuseas e vômitos } \\
\text { induzidos pela quimioterapia, } \\
\text { sem produzir efeitos colaterais. }\end{array}$ & Chinesa \\
\hline $\begin{array}{l}\text { C8: Shin N, } \\
\text { et al; } 2018^{(23)} \text {. } \\
\text { Effect of } \\
\text { auricular } \\
\text { acupressure } \\
\text { on nausea, } \\
\text { vomiting, and } \\
\text { retching in } \\
\text { patients with } \\
\text { colorectal } \\
\text { cancer } \\
\text { receiving } \\
\text { chemotherapy. }\end{array}$ & $\mathrm{EQE}^{\mathrm{a}}$ & $\begin{array}{c}\text { Avaliar os } \\
\text { efeitos da } \\
\text { acupressão } \\
\text { auricular na } \\
\text { náusea e vômito } \\
\text { em pacientes } \\
\text { com câncer } \\
\text { colorretal } \\
\text { recebendo } \\
\text { quimioterapia. }\end{array}$ & $\begin{array}{l}50 \text { participantes } \\
\text { com câncer } \\
\text { colorretal, } \\
\text { a partir do } \\
\text { segundo } \\
\text { ciclo de } \\
\text { quimioterapia, } \\
\text { divididos em } \\
\text { dois grupos } \\
\text { de } 25 \text { cada: } \\
\text { experimental e } \\
\text { controle. }\end{array}$ & \begin{tabular}{|} 
Auriculoterapia com \\
sementes, durante \\
2 dias. Pontos \\
auriculares: zero, \\
estômago, tronco \\
cerebral, shenmen \\
e coração. O \\
grupo controle não \\
recebeu nenhuma \\
intervenção.
\end{tabular} & $\begin{array}{l}\text { Versão Coreana do } \\
\text { Index of Nausea, } \\
\text { Vomiting, and } \\
\text { Retching (INVR) } \\
\text { para medir a } \\
\text { frequência, a } \\
\text { angústia e a } \\
\text { duração associadas } \\
\text { à náusea e à } \\
\text { quantidade de } \\
\text { vômitos. }\end{array}$ & $\begin{array}{l}\text { O grupo experimental } \\
\text { apresentou náusea } \\
\text { significativamente menor } \\
\text { ( } \mathrm{p}=0,011) \text { e ânsia de vômito } \\
\text { ( } \mathrm{p}=0,014) \text { do que o grupo } \\
\text { controle. Os resultados } \\
\text { propõem que a auriculoterapia } \\
\text { é eficaz no alívio de náuseas } \\
\text { e vômito após a quimioterapia } \\
\text { e que esse procedimento seja } \\
\text { utilizado como intervenção } \\
\text { de enfermagem, pois ajuda a } \\
\text { melhorar a qualidade de vida } \\
\text { dos pacientes com câncer } \\
\text { colorretal. }\end{array}$ & Chinesa \\
\hline \multicolumn{8}{|c|}{ Grupo 4: Ondas de calor } \\
\hline $\begin{array}{l}\text { C4: Viel E, et } \\
\text { al; } 2016^{(20)} \text {. } \\
\text { Efficiency } \\
\text { of auricular } \\
\text { acupuncture } \\
\text { in climacteric } \\
\text { symptoms } \\
\text { after cancer } \\
\text { treatments }\end{array}$ & $\mathrm{EOR}^{\mathrm{c}}$ & $\begin{array}{c}\text { Destacar a } \\
\text { eficiência da } \\
\text { auriculoterapia } \\
\text { no tratamento } \\
\text { de ondas de } \\
\text { calor pós- } \\
\text { terapêuticas em } \\
\text { pacientes com } \\
\text { câncer. }\end{array}$ & $\begin{array}{l}41 \text { participantes } \\
\text { com câncer } \\
\text { e sintomas } \\
\text { de fogachos, } \\
\text { especialmente } \\
\text { relacionadas a } \\
\text { quimioterapia } \\
\text { e/ou } \\
\text { hormonioterapia. }\end{array}$ & \begin{tabular}{|c|} 
Auriculoterapia \\
com agulhas \\
semipermanentes \\
ou crioterapia. \\
Pontos auriculares: \\
rinencéfalo, \\
hormônios FSH e \\
LH, hipotálamo \\
anterior, epífise, \\
ponto principal do \\
sistema nervoso \\
simpático e plexo \\
tireoidiano. Variação \\
de 1 a 5 aplicações \\
com intervalo de pelo \\
menos 4 semanas \\
entre duas sessões. \\
\end{tabular} & $\begin{array}{c}\text { Avaliação } \\
\text { da eficácia } \\
\text { autorrelatada } \\
\text { registrada em } \\
\text { prontuário. }^{* * *}\end{array}$ & $\begin{array}{l}\text { Foi reconhecido que no } \\
\text { mínimo } 3 \text { sessões são } \\
\text { necessárias antes de julgar } \\
\text { se a intervenção falhou. E } \\
69 \% * * \text { dos participantes do } \\
\text { estudo notaram uma melhora } \\
\text { do quadro dos fogachos. A } \\
\text { auriculoterapia é um método } \\
\text { eficaz entre os pacientes que } \\
\text { apresentaram sintomas da } \\
\text { menopausa relacionados ao } \\
\text { tratamento do câncer e tem } \\
\text { sido considerada segura e } \\
\text { barata para tratar as ondas de } \\
\text { calor. }\end{array}$ & Francesa \\
\hline \multicolumn{8}{|c|}{ Grupo 5: Dispneia } \\
\hline $\begin{array}{l}\text { C5: Strong RA, } \\
\text { et al; } 2015^{(21)} \text {. } \\
\text { pilot evaluation } \\
\text { of auricular } \\
\text { acupressure } \\
\text { in end-stage } \\
\text { lung cancer } \\
\text { patients. }\end{array}$ & $\mathrm{ECR}^{\mathrm{b}}$ & \begin{tabular}{|} 
Avaliar os \\
efeitos da \\
terapia de \\
acupressão \\
auricular \\
padronizada \\
sobre a \\
intensidade \\
da dispneia \\
e saturação \\
de oxigênio \\
em pacientes \\
com câncer \\
de pulmão em \\
estágio terminal.
\end{tabular} & $\begin{array}{l}11 \text { participantes } \\
\text { com um } \\
\text { diagnóstico } \\
\text { câncer de } \\
\text { pulmão foram } \\
\text { randomizados } \\
\text { e designados } \\
\text { para uma das } \\
\text { três condições } \\
\text { de tratamento: } \\
\text { (1) Grupo } \\
\text { controle; (2) } \\
\text { Grupo placebo } \\
\text { e (3) Grupo } \\
\text { experimental. }\end{array}$ & $\begin{array}{l}\text { (1) Cuidado padrão; } \\
\text { (2) Auriculoterapia } \\
\text { falsa com sementes } \\
\text { em local não } \\
\text { associado ao pulmão; } \\
\text { e (3) Auriculoterapia } \\
\text { com sementes* } \\
\text { em localização } \\
\text { específica da função } \\
\text { pulmonar em ambas } \\
\text { as orelhas. Terapia } \\
\text { auricular verdadeira } \\
\text { e falsa com sementes } \\
\text { mantidas por } 3 \text { dias. }\end{array}$ & \begin{tabular}{|c|} 
Escala Cancer \\
Dyspnea Scale \\
(CDS) de 12 \\
itens avalia três \\
dimensões da \\
dispneia (sensação \\
de esforço, sensação \\
de ansiedade \\
e sensação de \\
desconforto) usando \\
uma escala Likert \\
de 5 pontos para \\
responder a cada \\
item. A saturação de \\
oxigênio foi medida \\
pelo oxímetro \\
de pulso em oito \\
momentos.
\end{tabular} & $\begin{array}{c}\text { As análises estatísticas } \\
\text { sugerem a presença de um } \\
\text { efeito significativo do grupo } \\
\text { experimental na sensação } \\
\text { de esforço da dispneia } \\
\text { (p=0,43), mas os valores da } \\
\text { oximetria não se alteraram. } \\
\text { A intervenção parece ser } \\
\text { viável e potencialmente } \\
\text { útil, foi bem tolerada pelos } \\
\text { participantes e não apresentou } \\
\text { efeitos colaterais. Assim, essa } \\
\text { população, embora frágil, é um } \\
\text { foco apropriado para estudos de } \\
\text { intervenção destinados a reduzir } \\
\text { a dispneia, uma vez que o ônus } \\
\text { do desconforto é minimizado o } \\
\text { máximo possível. }\end{array}$ & Chinesa \\
\hline
\end{tabular}


...continuação

\begin{tabular}{|c|c|c|c|c|c|c|c|}
\hline Artigo & $\begin{array}{l}\text { Tipo de } \\
\text { Estudo }\end{array}$ & Objetivo & Amostra & Intervenção & Mensuração & Resultados/ Conclusões & $\begin{array}{l}\text { Linha de } \\
\text { tratamento }\end{array}$ \\
\hline \multicolumn{8}{|c|}{ Grupo 6: Fadiga } \\
\hline $\begin{array}{l}\text { C6: Yeh } \mathrm{CH}, \\
\text { et al; } 2015^{(5)} \text {. }\end{array}$ & \multicolumn{7}{|c|}{ Descrito } \\
\hline \multicolumn{8}{|c|}{ Grupo 6: Distúrbio do sono } \\
\hline $\begin{array}{l}\text { C6: Yeh } \mathrm{CH} \text {, } \\
\text { et al; } 2015^{(5)} \text {. }\end{array}$ & \multicolumn{7}{|c|}{$\begin{array}{c}\text { Descrito no Grupo 1, porém também se enquadra nos Grupos } 6 \text { e } 7 \text { por abordar o conjunto de sintomas: Dor, fadiga e } \\
\text { distúrbio do sono. }\end{array}$} \\
\hline $\begin{array}{l}\text { C9: Kuo } \\
\text { HC, et al; } \\
2018^{(24)} \text {. Pilot } \\
\text { randomized } \\
\text { controlled } \\
\text { trial of } \\
\text { auricular point } \\
\text { acupressure } \\
\text { for sleep } \\
\text { disturbances } \\
\text { in women with } \\
\text { ovarian cancer. }\end{array}$ & $\mathrm{ECR}^{\mathrm{b}}$ & $\begin{array}{c}\text { Avaliar a } \\
\text { viabilidade, } \\
\text { aceitabilidade } \\
\text { e eficácia da } \\
\text { acupressão } \\
\text { auricular pontual } \\
\text { para reduzir } \\
\text { distúrbios } \\
\text { do sono em } \\
\text { mulheres com } \\
\text { câncer de ovário } \\
\text { em tratamento } \\
\text { quimioterápico. }\end{array}$ & $\begin{array}{l}47 \text { mulheres } \\
\text { com câncer } \\
\text { de ovário com } \\
\text { alto nível de } \\
\text { distúrbios } \\
\text { do sono em } \\
\text { tratamento } \\
\text { quimioterápico, } \\
\text { foram } \\
\text { randomizadas } \\
\text { para um grupo } \\
\text { intervenção ( } \mathrm{n} \\
\text { = 23) ou um } \\
\text { grupo controle } \\
(\mathrm{n}=24) .\end{array}$ & $\begin{array}{c}\text { Auriculoterapia, } \\
\text { durante } 6 \text { semanas, } \\
\text { com sementes. } \\
\text { Pontos auriculares: } \\
\text { ansiedade, coração, } \\
\text { subcórtex e } \\
\text { endócrino, além } \\
\text { de práticas de } \\
\text { higiene do sono. } \\
\text { E o grupo controle } \\
\text { as participantes } \\
\text { receberam apenas } \\
\text { práticas de higiene do } \\
\text { sono. }\end{array}$ & \begin{tabular}{|} 
Índice de qualidade \\
do sono Pittsburgh \\
Sleep Quality \\
Index (PSQI) e um \\
questionário de \\
autorrelato.
\end{tabular} & $\begin{array}{c}\text { Os resultados indicam que } \\
\text { depois de receber o terceiro } \\
\text { ciclo de quimioterapia, foram } \\
\text { observados níveis elevados } \\
\text { de sono perturbado entre os } \\
\text { dois grupos, e a intervenção } \\
\text { com auriculoterapia foi eficaz } \\
\text { para melhorar o sono } 13-19 \% \\
\text { nas pontuações do índice } \\
\text { de qualidade do sono, em } \\
\text { comparação com o controle } \\
\text { (p<0,001). A terapia auricular } \\
\text { parece ser uma abordagem } \\
\text { promissora, viável e eficaz para } \\
\text { ajudar mulheres com câncer } \\
\text { de ovário com distúrbios do } \\
\text { sono. }\end{array}$ & Chinesa \\
\hline $\begin{array}{l}\text { C11: Hughes } \\
\text { JG, et al; } \\
2015^{(26)} \text {. A } \\
\text { feasibility study } \\
\text { of auricular } \\
\text { therapy } \\
\text { and self- } \\
\text { administered } \\
\text { acupressure } \\
\text { for insomnia } \\
\text { following } \\
\text { cancer } \\
\text { treatment. }\end{array}$ & $\mathrm{ECR}^{\mathrm{b}}$ & $\begin{array}{c}\text { Fornecer dados } \\
\text { preliminares } \\
\text { sobre a eficácia } \\
\text { de duas } \\
\text { variantes de } \\
\text { auriculoterapia } \\
\text { e acupressão } \\
\text { autoadministrada } \\
\text { no alívio da } \\
\text { insônia em } \\
\text { sobreviventes do } \\
\text { câncer. }\end{array}$ & \begin{tabular}{|}
7 participantes \\
com diagnóstico \\
de câncer após \\
o término do \\
tratamento, \\
randomizados \\
para uma das \\
três condições \\
de tratamento: \\
(1) Terapia \\
auricular $(n=4) ;$ \\
$(2)$ acupressão \\
corporal \\
autoadministrada \\
$(\mathrm{n}=1) ;$ e $(3)$ sem \\
tratamento $(\mathrm{n}=2)$.
\end{tabular} & $\begin{array}{l}\text { A terapia auricular } \\
\text { (1) foi realizada } \\
\text { com sementes, } \\
\text { bilateralmente, nos } \\
\text { pontos auriculares: } \\
\text { shenmen, insônia, } \\
\text { coração, fígado, } \\
\text { rim e subcórtex. } \\
\text { A acupressão } \\
\text { corporal (2). E o } \\
\text { terceito grupo não } \\
\text { recebeu tratamento } \\
\text { adicional (3). Todos } \\
\text { os braços do estudo } \\
\text { receberam tratamento } \\
\text { semanalmente, } \\
\text { durante } 5 \text { semanas, } \\
\text { de acordo com o } \\
\text { respectivo grupo. }\end{array}$ & $\begin{array}{c}\text { Índice de qualidade } \\
\text { do sono de } \\
\text { Pittsburgh (PSQI) } \\
\text { que mede a } \\
\text { qualidade do sono } \\
\text { e o questionário } \\
\text { MYCaW, que é } \\
\text { individualizado } \\
\text { e avalia } \\
\text { preocupações e } \\
\text { o bem-estar, e foi } \\
\text { desenvolvido para } \\
\text { avaliar terapias } \\
\text { complementares } \\
\text { no tratamento do } \\
\text { câncer. }\end{array}$ & $\begin{array}{c}\text { O escore global do PSQI } \\
\text { foi melhor no grupo de } \\
\text { acupressão do que no } \\
\text { grupo sem tratamento } \\
\text { (p<0,00001). Apesar do } \\
\text { tamanho da amostra muito } \\
\text { limitado, todos os pacientes } \\
\text { alocados para receber terapia } \\
\text { auricular ou autoacupressão } \\
\text { experimentaram melhorias } \\
\text { relevantes em seus sintomas de } \\
\text { insônia. A terapia auricular é } \\
\text { uma intervenção não invasiva, } \\
\text { que parece segura e aceitável } \\
\text { para pacientes com câncer, e } \\
\text { pode representar tratamento } \\
\text { eficaz para a síndrome da } \\
\text { insônia crônica. }\end{array}$ & Chinesa \\
\hline
\end{tabular}

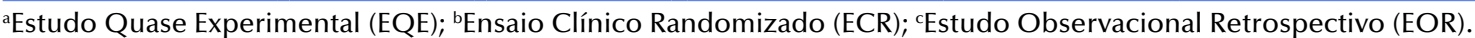

* Os estudos C5 e C10 não especificaram os pontos auriculares. ${ }^{* *}$ O estudo C4 não apresenta o valor de p. ${ }^{* *} \mathrm{O}$ estudo C4 não utiliza escala para avaliar fogachos.

Quanto à população alvo dos estudos, todas as amostras foram constituídas por pacientes oncológicos adultos e idosos, que estavam em acompanhamento pelos respectivos serviços: em tratamento oncológico convencional, sobreviventes de câncer e pacientes em cuidados paliativos.

No Quadro 4 são apresentados os tipos de câncer dos pacientes participantes dos estudos selecionados:

Quadro 4 - Tipos de câncer abordados nos artigos selecionados - Niterói, RJ, Brasil, 2019.

\begin{tabular}{|l|c|}
\hline Tipo de Câncer & Identificação dos Artigos \\
\hline Câncer de Mama & C1, C2, C3, C4, C6 e C11 \\
\hline Câncer de Próstata & C4 \\
\hline Câncer de Pulmão & C5 e C10 \\
\hline Câncer Colorretal & C8 e C11 \\
\hline Câncer de Ovário & C9 \\
\hline Não especificado & C7 \\
\hline
\end{tabular}

Em relação ao número de participantes, houve uma grande diferença entre os estudos, que variaram de sete a 341 indivíduos, e quanto à idade a variação também teve um intervalo significativo de 19 a 93 anos. Outro dado importante relacionado às características dos pacientes das pesquisas, é o sexo, em cinco estudos $(45,5 \%)$ esses grupos foram formados por participantes de ambos os sexos, quatro $(36,5 \%)$ apenas com grupos do sexo feminino, relacionados aos cânceres de ovário e de mama e, em dois estudos (18\%) não foi especificado o sexo dos participantes.

Além do tipo de câncer, foi constatado que em sete estudos (64\%) os pacientes estavam sendo submetidos a algum tipo de tratamento convencional ao serem abordados para a aplicação de auriculoterapia, como: Quimioterapia, Hormonioterapia e Cirurgia. Somente em dois estudos (18\%), C5 e C11, não havia participantes submetidos a tratamentos específicos, e sim no acompanhamento pós-tratamento e em cuidados paliativos. Já nos artigos C6 e 
C7 (18\%), os autores não especificaram em qual fase do tratamento os participantes se encontravam.

A intervenção de auriculoterapia em dez estudos (91\%) foi realizada através da acupressão auricular com sementes e somente no estudo C4 (9\%) foram utilizadas agulhas semipermeáveis e crioterapia para tal procedimento. No estudo C9, específico para alívio da constipação pós-operatória, além da acupressão auricular com sementes foi adicionado acupuntura corporal. Já no artigo C11, que aborda a insônia no pós-tratamento de pacientes oncológicos, foram utilizados três braços de intervenção com randomização, acupressão auricular, acupuntura corporal autoadministrada ou sem tratamento.

Em sete estudos (64\%), a utilização da acupressão auricular com sementes foi acompanhada de instrução aos participantes para aplicação de pressão manual nas sementes em todos os pontos auriculares, três vezes por dia (manhã, tarde e noite) durante três minutos cada. Em um único estudo (9\%), os participantes foram instruídos a aplicar pressão manual nas sementes, quatro vezes ao dia durante cinco minutos e, em outro estudo isolado (9\%), os pacientes foram orientados a aplicar pressão manual nas sementes somente uma vez, à noite, durante um minuto. Dois artigos (18\%) não mencionaram esse tipo de orientação aos pacientes, o estudo $\mathrm{C} 4$ que utilizou a auriculoterapia com agulhas e crioterapia e o estudo $\mathrm{C} 5$, que abordou pacientes com câncer de pulmão, com desconforto respiratório em estágio terminal.

Alguns autores referiram efeitos colaterais locais mínimos e suportáveis da intervenção da auriculoterapia em sete estudos $(63,5 \%)$, somente um estudo (9\%) relatou ausência desses efeitos e outros três $(27,5 \%)$ não apresentaram nada a respeito em seus artigos. Todos os trabalhos analisados (100\%) expuseram efeitos positivos da auriculoterapia sobre os sintomas de pacientes com câncer e/ou seu tratamento e indicaram o uso desta intervenção.

Para determinar a eficácia da intervenção de auriculoterapia sobre os sintomas tratados, dez estudos (91\%) utilizaram escalas para quantificar a melhora dos mesmos e um artigo (9\%) não descreveu qual forma de mensuração foi aplicada.

E em relação às linhas de tratamento empregadas para terapia auricular, as publicações trouxeram predomínio da linha de tratamento chinesa com dez estudos (91\%) e somente um artigo explicitou a utilização da linha francesa.

\section{DISCUSSÃO}

A visão mercantilista na saúde predominante na sociedade é caracterizada por dispensar mais tempo e recursos focados nas doenças, com uso e desenvolvimento desenfreado de tecnologias e de medicamentos, visando geração de lucros e fragmentação dos tratamentos do paciente em especialidades, por não conseguirem perceber a totalidade do ser humano. Nesse contexto, o progressivo avanço adquirido pelas práticas integrativas e complementares (PICS) tem ganhado destaque e pode ser entendido como a expressão de um movimento com novas formas de aprender e de praticar a saúde. Trata-se de revelar que existem práticas capazes de fazer a diferença, através de modos alternativos de promover saúde, não lucrativos, menos onerosos, mais humanizados e mais aptos a cuidar do ser humano como um todo ${ }^{(27)}$.

Pesquisas têm demonstrado que as práticas integrativas e complementares (PICS) em saúde podem ser utilizadas como estratégias de enfrentamento de diversas especialidades na área da saúde, inclusive na oncologia, devido ao fato de ter o tratamento excessivamente invasivo, apresentar limites terapêuticos muito evidentes, danos terapêuticos relevantes e com isso afetar, cada vez mais, a qualidade de vida dos pacientes ${ }^{(6)}$.

Diante disso, a alta prevalência de sintomas não resolvidos para pacientes com câncer indica que um melhor gerenciamento destes sintomas é necessário, pois além de toda a carga que a doença traz, os pacientes também enfrentam os efeitos colaterais dos tratamentos ${ }^{(5)}$. Os resultados do presente estudo de revisão sugerem que houve predominância de estudos (64\%), em que os sintomas relatados pelos pacientes estavam relacionados aos efeitos colaterais proveniente dos tratamentos realizados.

Um estudo japonês menciona que pacientes com câncer, geralmente, tomam vários medicamentos para reduzir os efeitos colaterais da quimioterapia, mas preferem medidas de intervenção não medicamentosas ${ }^{(28)}$. Por meio dos resultados, foi identificado que a maioria dos estudos analisados $(45,5 \%)$, nesta revisão, com o uso de auriculoterapia se concentrou no continente Asiático, que já traz a cultura da Medicina Tradicional Chinesa enraizada, o que pode justificar as numerosas pesquisas nesses locais e a grande aceitação dos pacientes por essas práticas.

Apesar disso, as pesquisas relacionadas com as práticas integrativas e complementares (PICS) estão se expandindo para o Ocidente, principalmente, nos Estados Unidos, em que foram encontrados quatro artigos (36,5\%) desenvolvidos sobre auriculoterapia em Oncologia. Uma confirmação deste interesse é a diretriz produzida pela Sociedade para Oncologia Integrativa (SIO), baseada em evidências sobre o uso de terapias integrativas durante e após o tratamento do câncer de mama, que foi determinado como relevante pela Sociedade Americana de Oncologia Clínica (ASCO). Entre as principais recomendações incluem: a musicoterapia, a meditação e a yoga para a redução da ansiedade e de estresse; a meditação, o relaxamento, a yoga, a massagem e a musicoterapia são recomendados para transtornos de depressão e do humor; a meditação e a yoga são recomendados para melhorar a qualidade de vida; e o uso da acupressão e a acupuntura são recomendadas para reduzir a náusea e o vômito induzidos pela quimioterapia ${ }^{(29)}$.

A auriculoterapia é um dos métodos terapêuticos mais utilizados em diferentes países, sendo extensivamente aplicado por médicos e enfermeiros como medida preventivo-terapêutica ${ }^{(19)}$. No campo da enfermagem, a acupressão auricular, em vez da acupuntura com agulhas, tem sido muito utilizada, pois não há a necessidade de profissionais especialistas em acupuntura para a aplicação dessa prática e sim profissionais com curso de capacitação na área ${ }^{(22)}$. 
A aceitabilidade destes profissionais de saúde e facilidade na aplicação da técnica pode justificar o dado exposto no resultado da presente revisão com dez artigos (91\%) referindo a participação de enfermeiros nos estudos de intervenção com auriculoterapia.

A utilização da acupressão auricular com sementes está presente em nove estudos (91\%) desta revisão, sendo uma maneira potencialmente eficaz de controlar diversos sintomas. Por ser uma intervenção não invasiva, não traz efeitos colaterais como os que podem ser causados por agulhas de acupuntura, como a infecção local e a fobia causada pela inserção da agulha ${ }^{(22)}$. Além disso, o uso de sementes tem menos custos, sendo seguro, rápido e também adaptável às condições ambientais e pode ser implementada na prática clínica como uma ótima opção dentro das práticas integrativas e complementares (PICS) ${ }^{(19)}$.

Em 2014, foi publicada uma revisão sistemática de literatura sobre os efeitos adversos da auriculoterapia, indicando que todos os efeitos relatados por oitenta e sete ensaios clínicos foram considerados como reações de curto prazo, leves e toleráveis, como: desconforto local, dor transitória, irritação na pele local e, em casos raros, tonteiras e pequenos sangramentos. Alguns desses sintomas eram potencialmente evitáveis e nenhum efeito adverso grave foi detectado. Como conclusões, os autores consideraram, com base nos achados, a segurança da auriculoterapia superior quando comparada a outras terapias alternativas ${ }^{(30)}$.

O estudo C6 mencionou que aproximadamente dois terços dos pacientes relataram desconforto auricular nos locais em que as sementes foram inseridas durante os primeiros dias de tratamento e que esses efeitos foram diminuindo gradualmente. No entanto, os participantes estavam dispostos a tolerar algum desconforto local, porque estavam motivados a tentar uma nova terapia depois de ter sofrido dor por um período prolongado ${ }^{(5)}$. Já o estudo C5 refere que os efeitos adversos da auriculoterapia relatados pelos participantes foram mínimos e locais, entre esses os mais comuns foram: dor, desconforto e prurido na orelha. Porém, nenhum participante abandonou o estudo devido a esses efeitos, o que implica que são toleráveis. Além disso, os participantes indicaram que quaisquer efeitos adversos foram menores em comparação com o sofrimento do câncer ${ }^{(21)}$. O que vai ao encontro dos resultados apresentados que mostram que sete artigos $(63,5 \%)$ confirmam a presença de efeitos colaterais leves e suportáveis frente aos benefícios apresentados.

Sendo assim, estimulando diferentes pontos auriculares através da auriculoterapia, uma série de distúrbios podem ser tratados, como o alívio da dor, quaisquer dores crônicas ou agudas; distúrbios psicológicos, como a ansiedade e a depressão; cessação do tabagismo e abuso de substâncias; adjuvante no tratamento da obesidade; náuseas e vômitos na gravidez; constipação; insônia, além dos sintomas relacionados ao câncer e seu tratamento ${ }^{(19)}$.

Os resultados da presente revisão indicam que o uso $\mathrm{da}$ auriculoterapia, em pacientes oncológicos, ofereceu melhora dos sintomas apresentados em todos os artigos
(100\%) e a maioria dos estudos (91\%) comprovou a eficácia da técnica através de escalas de mensuração dos sintomas. Assim, os sintomas referidos pelos pacientes com câncer e tratados com auriculoterapia foram: dor $(27,5 \%)$, constipação (18\%), náuseas e vômitos (18\%), fogachos (9\%), dispneia (9\%), fadiga (9\%) e insônia $(27,5 \%)$. Todos esses achados comprovam a diversidade de sintomas, que já foram estudados para a intervenção auriculoterapia em oncologia, porém nenhum se destacou em relação à quantidade de estudos e todos apresentaram porcentagens parecidas com o máximo de três artigos relacionados a um sintoma.

A realização da busca, em cinco bases de dados, com os descritores e as palavras-chave apresentados pode ter interferido nos resultados obtidos, apesar da busca de termos que abrangessem o universo da auriculoterapia. Esta revisão sintetiza as evidências sobre o uso da auriculoterapia para o alívio dos sintomas, em pacientes oncológicos, nos últimos cinco anos e fornece um direcionamento para que os enfermeiros possam refletir a respeito do uso desta prática integrativa e complementar nas suas atividades, visto que as intervenções farmacológicas usualmente utilizadas não dão conta de atender essa população e podem até causar prejuízos em função de interações medicamentosas ${ }^{(5)}$.

\section{CONCLUSÃO}

Os resultados desta revisão integrativa indicam que o uso $\mathrm{da}$ auriculoterapia em pacientes oncológicos proporciona melhora dos sintomas apresentados e os autores recomendam esta prática como uma intervenção de enfermagem segura e bem tolerada pelos pacientes, em que os benefícios superam os pequenos efeitos colaterais, que podem surgir com o procedimento.

A partir dos estudos analisados é possível afirmar que grande parte dos sintomas relatados pelos pacientes estava relacionada aos efeitos colaterais provenientes dos tratamentos realizados para o câncer. Além disso, os resultados também sugerem que a assistência de enfermagem oncológica assume um destaque, pois a maior parte dos estudos de intervenção com auriculoterapia contou com a participação de enfermeiros.

Nesse contexto, o enfermeiro oncologista tem um papel importante no alívio de diversos sintomas decorrentes do câncer, podendo usar diferentes técnicas para melhorar a qualidade de vida dos pacientes, aumentando a variedade de opções para os cuidados no sentido de favorecer a recuperação e a manutenção da saúde dos pacientes frente ao tratamento e a reabilitação.

No entanto, a quantidade de pesquisas sobre esse tema ainda é limitada, principalmente, no Brasil. E existe uma limitação também em relação à qualidade dos estudos realizados, já que dos onze artigos encontrados, somente três apresentou alto nível de evidência. Assim, mais estudos de qualidade ainda devem ser realizados para que se possa compreender melhor sobre a utilização da auriculoterapia nos diversos sintomas apresentados pelos pacientes oncológicos. 


\section{RESUMO}

Objetivo: Analisar evidências científicas na literatura do uso da auriculoterapia no alívio de sintomas relacionados ao câncer e/ou seu tratamento. Método: Revisão integrativa da literatura nas bases: MEDLINE, CINAHL, LILACS, SCOPUS e COCHRANE, nos últimos cinco anos e nos idiomas inglês, português e espanhol. Critérios de inclusão: estudos primários com o tema central. Critérios de exclusão: artigos de opinião, revisões e relato de experiência. Resultados: A busca resultou em 435 publicações e após quatro etapas de seleção restaram 11. A análise dos desenhos dos estudos mostrou que três deles $(27,5 \%)$ apresentaram nível de evidência alto, três $(27,5 \%)$ moderado, quatro (36\%) baixo e um (9\%) muito baixo. Os desfechos avaliados foram relacionados aos seguintes sintomas: dor, constipação, náuseas e vômitos, fogachos, dispneia, fadiga e insônia. E $100 \%$ das publicações expuseram efeitos positivos da auriculoterapia em oncologia. Conclusão: A auriculoterapia em pacientes oncológicos proporciona melhora dos sintomas e esta prática foi considerada uma intervenção segura e aceitável. Entretanto, é necessário ampliar estudos para obtenção de mais evidências favoráveis já que somente 3 estudos apresentaram alto nível de evidência.

\section{DESCRITORES}

Terapias Complementares; Auriculoterapia; Acupuntura Auricular; Neoplasias; Enfermagem Oncológica; Revisão.

\section{RESUMEN}

Objetivo: Analizar evidencias científicas en la literatura del uso de la auriculoterapia en el alivio de los síntomas relacionados al cáncer y/o su tratamiento. Método: Revisión integrativa de la literatura en las bases: MEDLINE, CINAHL, LILACS, SCOPUS y COCHRANE, en los últimos cinco años y en los idiomas inglés, portugués y español. Criterios de inclusión: estudios primarios con el tema central. Criterios de exclusión: artículos de opinión, revisiones y relato de la experiencia. Resultados: La busca resultó 435 publicaciones y después de cuatro etapas de selección restaran 11. El análisis de los diseños de los estudios mostró que tres de ellos $(27,5 \%)$ presentaran nivel de evidencia alto, tres $(27,5 \%)$ moderado, cuatro (36\%) bajo y un (9\%) muy bajo. Los desfechos avaliados fueran relacionados a los siguientes síntomas: dolor, constipación, náuseas y vómitos, sofocos, disnea, fatiga y insomnio. $100 \%$ de las publicaciones expusieran efectos positivos de la auriculoterapia en la oncología. Conclusión: La auriculoterapia en pacientes oncológicos proporciona mejora de los síntomas y esta práctica fue considerada una intervención segura y aceptable. Sin embargo, es necesario ampliar estudios para obtención de más evidencias favorables ya que solamente 3 estudios presentaran alto nivel de evidencia.

\section{DESCRIPTORES}

Terapias Complementarias; Auriculoterapia; Acupuntura Auricular; Neoplasias; Enfermería Oncológica; Revisión.

\section{REFERÊNCIAS}

1. Costa TC, Lopes M, Anjos ACY, Zago MMF. Chemotherapy-induced peripheral neuropathies: an integrative review of the literature. Rev Esc Enferm USP. 2015;49(2):335-45. http://dx.doi.org/10.1590/S0080-623420150000200020

2. Instituto Nacional de Câncer José Alencar Gomes da Silva. Estimativa 2018: incidência de câncer no Brasil [Internet]. Rio de Janeiro: INCA; 2018 [citado 2018 nov. 03]. Disponível em: http://www1.inca.gov.br/estimativa/2018/estimativa-2018.pdf

3. Instituto Nacional de Câncer José Alencar Gomes da Silva. ABC do câncer: abordagens básicas para o controle do câncer [Internet]. Rio de Janeiro: INCA; 2017 [citado 2018 nov. 03]. Disponível em: https://www.inca.gov.br/sites/ufu.sti.inca.local/files//media/document// livro-abc-3ed-8a-prova.pdf

4. Curtinaz ML, Muniz RM, Amaral DED, Viegas AC, Pinto BK, Barboza MCN. O contexto de adoecimento do homem com câncer de pulmão. Rev Esp Ciênc Saúde [Internet]. 2017 [citado 2018 set. 28];5(1):4-19. Disponível em: http://revistaeletronica.unicruz.edu.br/index.php/ enfermagem/article/view/5489/1053

5. Yeh $\mathrm{CH}$, Chien LC, Lin WC, Bovbjerg DH, van Londen GJ. Pilot randomized controlled trial of auricular point acupressure to manage symptom clusters of pain, fatigue, and disturbed sleep in breast cancer patients. Cancer Nurs. 2016;39(5):402-10. DOI: 10.1097/NCC.0000000000000303

6. Luz MT. Cultura contemporânea e medicinas alternativas: novos paradigmas em saúde no fim do século XX. Physis [Internet]. 2005 [citado 2018 nov. 07];15 Suppl:145-76. Disponível em: http://www.scielo.br/pdf/physis/v15s0/v15s0a08.pdf

7. Bonassa EMA, Gato MIR. Terapêutica oncológica para enfermeiros e farmacêuticos. $4^{a}$ ed. São Paulo: Atheneu; 2012.

8. Brasil. Ministério da Saúde. Política nacional de práticas integrativas e complementares no SUS: atitude de ampliação de acesso [Internet]. Brasília; 2015 [citado 2018 set. 28]. Disponível em: http://bvsms.saude.gov.br/bvs/publicacoes/politica_nacional_praticas_integrativas_ complementares_2ed.pdf

9. Brasil. Ministério da Saúde. Portaria $\mathrm{n}^{\circ} 702$, de 21 de março de 2018 . Altera a Portaria de Consolidação ${ }^{\circ} 2 / \mathrm{GM} / \mathrm{MS}$, de 28 de setembro de 2017, para incluir novas práticas na Política Nacional de Práticas Integrativas e Complementares - PNPIC [Internet]. Brasília; 2018 [citado 2019 ago. 28]. Disponível em: http://bvsms.saude.gov.br/bvs/saudelegis/gm/2018/prt0702_22_03_2018.html

10. Conselho Federal de Enfermagem. Resolução COFEN no 500/2015, de 8 dezembro de 2015. Revoga, expressamente, a Resolução Cofen $\mathrm{n}^{\circ}$ 197, de 19 de março de 1997, a qual dispõe sobre o estabelecimento e reconhecimento de Terapias Alternativas como especialidade e/ou qualificação do profissional de Enfermagem, e dá outras providências [Internet]. Brasília; 2015 [citado 2019 ago. 28]. Disponível em: http://www.cofen.gov.br/resolucao-cofen-no-05002015_36848.html

11. Prado JM, Kurebayashi LFS, Silva MJP. Experimental and placebo auriculotherapy for stressed nurses randomized controlled trial. Rev Esc Enferm USP. 2018;52:e03334. DOI: http://dx.doi.org/10.1590/s1980-220x2017030403334

12. Polit DF, Beck CT. Fundamentos de pesquisa em enfermagem: avaliação de evidências para a prática da enfermagem. $9^{a}$ ed. Porto Alegre: Artmed; 2019.

13. Mendes KDS, Silveira RCCP, Galvão CM. Revisão Integrativa: método de pesquisa para incorporação de evidências na saúde e na enfermagem. Texto Contexto Enferm. 2008; 17(4):758-64. DOI: http://dx.doi.org/10.1590/S0104-07072008000400018

14. Souza MT, Silva MD, Carvalho R. Revisão integrativa: o que é e como fazer. Einstein [Internet]. 2010 [citado 2018 nov. 09];8(1 Pt 1):102-6. Disponível em: http://www.scielo.br/pdf/eins/v8n1/pt_1679-4508-eins-8-1-0102 
15. Ursi ES, Gavão CM. Prevenção de lesões de pele no perioperatório: revisão integrativa da literatura. Rev Latino Am Enfermagem. 2006;14(1):124-31. DOI: http://dx.doi.org/10.1590/S0104-11692006000100017

16. Galvão TF, Pereira MG. Avaliação da qualidade da evidência de revisões sistemáticas. Epidemiol Serv Saúde. 2015;24(1):173-5. DOI: http://dx.doi.org/10.5123/S1679-49742015000100019

17. Yeh CH, Lin WC, Kwai-Ping Suen L, Park NJ, Wood LJ, van Londen GJ, et al. Auricular point acupressure to manage aromatase inhibitor-induced arthralgia in postmenopausal breast cancer survivors: a pilot study. Oncol Nurs Forum. 2017;44(4):476-87. DOI: 10.1188/17.ONF.476-487

18. Shin J, Park H. Effects of auricular acupressure on constipation in patients with breast cancer receiving chemotherapy: a randomized control trial. West J Nurs Res. 2018;40(1):67-83. DOI: 10.1177/0193945916680362

19. Eghbali M, Yekaninejad MS, Varaei S, Jalalinia SF, Samimi MA, Sa'atchi K. The effect of auricular acupressure on nausea and vomiting caused by chemotherapy among breast cancer patients. Complement Ther Clin Pract. 2016;24:189-94. DOI: 10.1016/j.ctcp.2016.06.006

20. Viel E, Vanoli A, Melis A, Rocher F, Schipman B, Truong D. Efficiency of auricular acupuncture in climacteric symptoms after cancer treatments. Climacteric. 2016;19(3):274-8. DOI: 10.3109/13697137.2016.1164135

21. Strong RA, Georges JM, Connelly CD. Pilot evaluation of auricular acupressure in end-stage lung cancer patients. J Palliat Med. 2016;19(5):556-8. DOI: 10.1089/jpm.2015.0347

22. Yeh $\mathrm{CH}$, Chien LC, Chiang YC, Ren D, Suen LK. Auricular point acupressure as an adjunct analgesic treatment for cancer patients: a feasibility study. Pain Manag Nurs. 2015;16(3):285-93. DOI: 10.1016/j.pmn.2014.08.005

23. Shin N, Park J. Effect of auricular acupressure on nausea, vomiting, and retching in patients with colorectal cancer receiving chemotherapy. Korean J Adult Nurs. 2018;30(3):227-34. DOI: https://doi.org/10.7475/kjan.2018.30.3.227

24. Kuo HC, Tsao Y, Tu HY, Dai ZH, Creedy DK. Pilot randomized controlled trial of auricular point acupressure for sleep disturbances in women with ovarian cancer. Res Nurs Health. 2018;41(5):469-79. DOI: 10.1002/nur.21885

25. Li Y, Qi D, Gong L, Qu H, Xu B, Wen X, et al. Effect of auricular points treatment combined with acupoints application in patients with constipation after lung cancer surgery. J Cancer Res Ther. 2017;13(5):844-8. DOI: 10.4103/jcrt.JCRT_709_17

26. Hughes JG, Towler P, Storey L, Wheeler SL, Molassiotis A. A feasibility study of auricular therapy and self-administered acupressure for insomnia following cancer treatment. Eur J Integr Med. 2015;7(6):623-7. DOI: https://doi.org/10.1016/j.eujim.2015.08.003

27. Telesi Júnior E. Práticas integrativas e complementares em saúde, uma nova eficácia para o SUS. Estudos Av. 2016;30(86):99-112. DOI: http://dx.doi.org/10.1590/S0103-40142016.00100007

28. Hanai A, Ishiguro H, Sozu T, Tsuda M, Arai H, Mitani A, et al. Effects of a self-management program on antiemetic-induced constipation during chemotherapy among breast cancer patients: a randomized controlled clinical trial. Breast Cancer Res Treat. 2016;155(1):99-107. DOI: $10.1007 / \mathrm{s} 10549-015-3652-4$

29. Lyman GH, Greenlee H, Bohlke K, Bao T, DeMichele AM, Deng GE, et al. Integrative therapies during and after breast cancer treatment: ASCO endorsement of the SIO clinical practice guideline. J Clin Oncol. 2018;36(25):2647-55. DOI: 10.1200/JCO.2018.79.2721

30. Tan JY, Molassiotis A, Wang T, Suen LKP. Adverse events of auricular therapy: a systematic review. Evid Based Complement Alternat Med. 2014;2014:506758. DOI: 10.1155/2014/506758 